\title{
Influence of Density on Sound Absorption Coefficient of Fibre Board
}

\author{
Anand Nandanwar, M. C. Kiran, K. Ch. Varadarajulu \\ Indian Plywood Industries Research and Training Institute, IPIRTI, Bangalore, India \\ Email: anandn@ipirti.gov.in
}

How to cite this paper: Nandanwar, A. Kiran, M.C. and Varadarajulu, K.Ch. (2017) Influence of Density on Sound Absorption Coefficient of Fibre Board. Open Journal of Acoustics, 7, 1-9. https://doi.org/10.4236/oja.2017.71001

Received: October 13, 2016

Accepted: January 23, 2017

Published: January 26, 2017

Copyright (C) 2017 by authors and Scientific Research Publishing Inc. This work is licensed under the Creative Commons Attribution International License (CC BY 4.0).

http://creativecommons.org/licenses/by/4.0/

(c) (†) Open Access

\begin{abstract}
For acoustic applications such as theaters, cinema halls, auditoriums the data on acoustic properties i.e. sound absorption coefficient and sound transmission loss are required to evaluate the acoustic behavior of panel products and to facilitate the necessary design computations. Fibre boards are widely used in private and commercial buildings, but not much data are available on acoustic efficiency of fibre boards. The study was carried using acoustic pulse tester based on standing wave method for evaluating sound absorption coefficient. Wood fibre boards of different densities ranging from 200 to $800 \mathrm{~kg} / \mathrm{m}^{3}$ were taken and their sound absorption coefficients at frequencies ranging from $125 \mathrm{~Hz}$ to $4000 \mathrm{~Hz}$ were evaluated in third octave band. Noise reduction coefficient of the samples was also computed. From the study, it is observed that low density fibre board possess high sound absorption coefficient and noise reduction coefficient when compared with high density fibre boards. It was seen that sound absorption coefficient increases with decrease in density and vice versa.
\end{abstract}

\section{Keywords}

Sound Absorption Coefficient, Sound Transmission Loss, Acoustic Efficiency, Panel Products

\section{Introduction}

Data on acoustic properties i.e. sound absorption coefficient and sound transmission loss of materials are required to evaluate the acoustic behavior of material and to facilitate the necessary design computations for various applications such as theaters, cinema halls, auditoriums etc. While there is a plenty of information on foam based absorption, there is a lack of data related to acoustic properties of wood and wood based panel products. The study aims to generate data on sound absorption coefficient of wood based fibre boards of different 
densities and derive the correlation between sound absorption coefficient and density.

For room acoustics, materials with a porous or baffled surface or materials with hollow cavities are typically used to absorb and dissipate sound waves, rather than reflecting them as echo into the room. In most cases an acoustic paneling material is used in combination with an appropriate bearing construction such as fabric overlaid panels. In some cases, acoustic elements are also used as covering for air conditioning or for loudspeaker systems. Sound absorbing products/panels are used in rooms and working areas to diminish reflected sound and thereby to cut the sound levels in the room, enhance environments for speech and music listening and resist reverberation. Most widely used sound absorbing materials are sound absorbing ceiling tiles and soft furnishings and curtains. In addition to these, various other sound absorbing materials are used in sound recording studios, cinemas, theatres, broadcast, industries, vehicles, etc. Sound absorbing materials highly depend on their porosity. The standard way to specify the effectiveness of absorbent materials is with an absorption coefficient. This number ranges from 0 to 1.0 , with 0 being perfectly non-absorbent and 1.0 being 100 percent absorbent. Since all materials absorb more sound at particular frequencies as compared to other frequencies, hence the absorption coefficient values are expressed as a function of frequency.

The data obtained by the investigation will be beneficiary for the engineers for the necessary design computations for designing recording rooms, television studios, theatres, hospitals, auditoriums, hotels, homes, classrooms, lecture halls etc. It is sometimes useful to employ a single figure called the noise reduction coefficient (NRC) of the material which is the average of the absorption coefficients at 250,500, 1000 and $2000 \mathrm{~Hz}$ frequencies. One material may absorb mainly at low frequencies while another works best at higher frequencies, yet both can have similar NRC values. When sound waves strike a surface, the energy may be divided into three portions: the incident, reflected, and absorbed energy. For acoustical designing in architecture it is convenient to use an average absorption coefficient which is assumed to depend only on the physical characteristics of the material and not on the sound field. The sound absorption coefficient of any material depends on the angle at which the sound wave imposes upon the material and the sound frequency. The absorption coefficient is generally reported in the literature at frequencies of 125, 250, 500, 1000 and 2000 Hertz [1].

There are three basic methods of measuring sound absorption. The first method [2] comprises the use of a reverberation room giving results valid for random incidence in a diffuse sound field and is suitable for large objects, furniture, panels, etc. The second method comprises the use of an impedance tube, giving results valid for normal incidence in a plane wave sound field, which is suitable for testing small samples. This method is designed for measurements of absorption coefficient and specific acoustic impedance of small samples of circular-cut sound absorbing materials normally in the frequency range $50 \mathrm{~Hz}$ to $6.4 \mathrm{kHz}$. 
The setup contains a loudspeaker attached at one end of an impedance tube and the sample of the material is positioned at the other end. The loudspeaker produces broadband, stationary random sound waves. These disseminate as plane waves in the tube, hit the sample and are reflected resulting in a standing wave interference pattern. The third method is reflection method, giving results valid for direct (normal or oblique) incidence in a non-diffuse sound field [3].

In general, sound absorbing materials are resistive in nature, they are either fibrous, porous or in rather in few cases they are reactive resonators [4]. The fibrous medium usually consists of rock wool, glass or polyester fibers and they have high sound absorption coefficient. Aballea, et al. [5] studied three noise cancelation systems. The first one is based on an electromechanical transducers loaded passively to get an optimal damping around the resonance frequency of the disposal. In the second system the passive load is substituted by an active control to enhance acoustic properties of device. The last strategy consists on a control of the first modal frequencies of a room to decrease the low frequency background noise level; the authors discussed their advantages and drawbacks. Seddeq [6] reviewed and showed the physical prosperities of materials like fibre properties i.e. fibre size, fibre type, material thickness, density, air flow resistance and porosity can change the sound absorption responsiveness.

Wang, et al. [7] investigated the sound absorption characteristics of a porous fibrous material, that is manufactured in Taiwan and he reported that the flow resistivity and the absorption coefficient are the important parameters that are determined. The measured flow resistivity of the glass and rock wool samples were scattered in a wider range and are usually greater than previously reported in the literature. Materials used for sound absorbing and dampening applications are often much softer than solid materials and have porosity higher than $90 \%$. Sikora et al. [8] presented the results of the expanded research program on sound absorbing properties of granular materials samples and he observed that there is a clear influence of layer thickness on the increase in sound absorption. Irrespective of the structure and bulk volume, the increase in layer thickness results in the increased average sound absorption coefficient.

Peng, et al. [9] investigated the physical and mechanical properties and the effects of the airflow resistivity of the materials and the depth of the cavities behind on sound-absorbing performance of the composite material. The results showed that the sound absorption coefficient decreased sharply as the flow resistivity went up and as the thickness of the cavities increased, the increase of the sound absorption coefficient in the low frequency range was noticed.

Kucuk and Korkmaz [10] study on the mix of natural fiber and nonwoven materials showed that the physical properties of the blending materials had a great influence on the sound absorption property of the mixed material. The results showed that as the thickness of the materials increased, the air permeability decreased and the flow resistance was improved, leading to sound absorption enhancement.

Some of the widely used panel products for acoustic applications are wood wool building slab [11] and low density particle board [12], however fibre boards 
has a potential of being an efficient acoustic panel product.

Delany [13] presented of an investigation into the acoustical properties of a range of fibrous absorbent materials. Measured values of characteristic impedance and propagation coefficient are shown to normalise as a function of frequency divided by flow-resistance and can be represented by simple power-law functions.

Garai [14] developed a new empirical model has to predict the flow resistivity, acoustic impedance and sound absorption coefficient of polyester fibre materials. The parameters of the model were adjusted to best fit the values of airflow resistivity and sound absorption coefficient measured over a set of 38 samples.

Garai [3] presented a series of experiments designed to put in evidence the differences between Reflection Index measurements performed in the mentioned critical conditions, according to the QUIESST guidelines, done using MLS (Maximum Length Sequence) or ESS (Exponential Swept-Sine) signals.

\section{Materials and Methods}

The samples from wood based Fibre boards were drawn from different sources/ manufactures having different densities. The samples were tested for sound absorption coefficient as per ASTM E1050-08 and IS 10420-1982 [15] [16].

Acoustic pulse tester of Bruel and Kjaer (B\&K) and a two microphone impendence measurement tube was used to measure sound absorption coefficient of small test samples in the frequency ranging from $50 \mathrm{~Hz}$ to $6.4 \mathrm{kHz}$ as per ASTM E1050-08. Using this equipment the sound absorption coefficient is derived by measuring the incident and reflected components of random or pseudo-random noise, which are generated inside the Impedance tube by the sound source. The reflected component is affected by the acoustic properties of the sample under test in which, the sample to be tested is kept in a sample holder placed at one end of a straight tube. A high-output acoustic driver as sound source is connected at the other end of the tube. A pair of microphones is positioned flush with the inner wall of the cylindrical tube near the sample holder of the tube as shown in Figure 1.

The sound absorption coefficient is defined as the ratio of absorbed energy to incident energy.

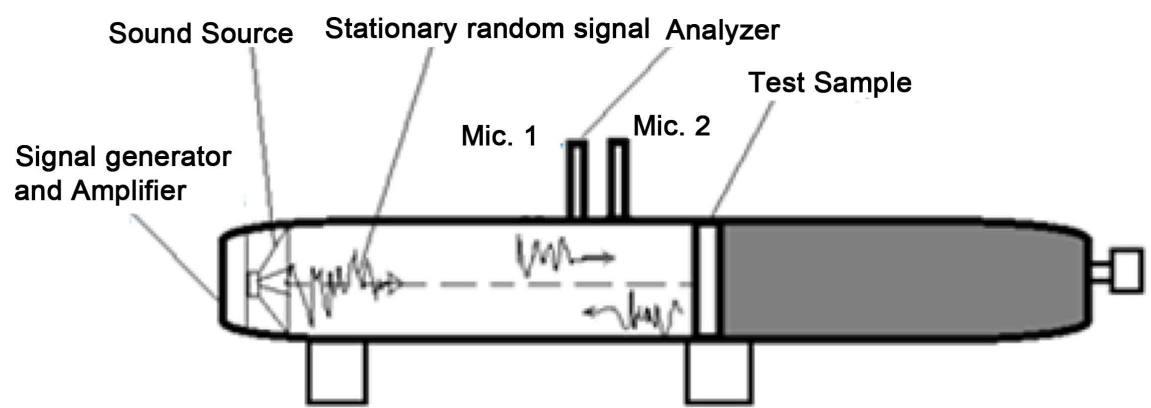

Figure 1. Conceptual drawing of two-microphone impedance method for sound absorption. 


$$
\square \alpha^{\prime}=E_{a} / E_{i}
$$

whereas the apparent sound absorption coefficient is defined as the ratio of all energy not reflected to incident energy, i.e.

$$
\alpha=E_{r} / E_{i}=\left(E_{a}+E_{t}\right) / E_{i}
$$

By Conservation of Energy

$$
E_{i}=E_{r}+E_{a}+E_{t}
$$

where,

$$
\begin{aligned}
& E_{i}=\text { Incident Energy } \\
& E_{r}=\text { Reflected energy } \\
& E_{a}=\text { Absorbed Energy } \\
& E_{t}=\text { Transmitted Energy }
\end{aligned}
$$

In general $\alpha$ is a function of the incident angle $\theta i$. The normal incidence value is denoted $\alpha n$.

In the study, a 1/12 octave real-time analyzer was employed (B\&K 2133), connected with a B\&K type 4206 tube. The absorption coefficient based on standing wave method is then computed. The sound pressure at two or more locations is measured and the complex transfer function calculated. It is then possible to determine the complex reflection coefficient, the sound absorption coefficient and the normal acoustic impedance of the material. ASTM E1050 - 08 [15] describes the Standard Test Method for Impedance and Absorption of Acoustical Materials Using a Tube, Two Microphones and a Digital Frequency Analysis System. Similarly IS 10420-1982 [16] gives the method of determination of sound absorption co-efficient of timber by standing wave method.

Specimens were collected from different fibre boards received for testing from outside agencies and their densities were evaluated as per IS 2380 Part 3 [17]. Fibre boards of thickness range of 18 - $25 \mathrm{~mm}$ with densities ranging from 200 to $800 \mathrm{~kg} / \mathrm{m}$, were taken for the study. Two sets of samples of diameters $100 \mathrm{~mm}$ and $29 \mathrm{~mm}$ were prepared for studying acoustic properties for frequencies ranging from $125 \mathrm{~Hz}$ to $1500 \mathrm{~Hz}$ and $1500 \mathrm{~Hz}$ to $4000 \mathrm{~Hz}$ respectively. The sound absorption coefficient of the samples was recorded. The average values for common frequencies from the two set of samples was noted. The noise reduction coefficient (NRC) was also calculated as the average of the absorption coefficients at 250, 500, 1000 and $2000 \mathrm{~Hz}$. Frequencies. The acoustic properties of fibre board are given in Table 1 and graph of density and noise reduction coefficient is shown in Figure 2 along with minimum prescribed limits of sound absorption coefficient specified in IS:3308 (1981) and IS: 3129 (1985) [11] [12] for comparison. The provided data are valid at normal incidence only.

\section{Result and Discussion}

The sound absorption coefficient of fibre board having different densities was evaluated. The effect of density on acoustic properties is given in Table 1 and Figure 2. The result shows that the noise reduction coefficient increases with decrease in density and vice versa. The relationship between NRC and density of 
Table 1. Sound Absorption coefficient of fibre boards of different densities.

\begin{tabular}{|c|c|c|c|c|c|c|c|c|c|c|c|c|c|c|}
\hline \multirow{2}{*}{ Sample No } & \multirow{2}{*}{$\begin{array}{c}\text { Density } \\
\mathrm{kg} / \mathrm{m}^{3}\end{array}$} & \multirow{2}{*}{$\begin{array}{c}\text { Thickness } \\
\mathrm{mm}\end{array}$} & \multicolumn{11}{|c|}{ FREQUENCY $(\mathrm{Hz})$} & \multirow{2}{*}{ NRC } \\
\hline & & & 0 & 125 & 250 & 500 & 1000 & 1500 & 2000 & 2500 & 3000 & 3500 & 4000 & \\
\hline 1 & 810 & 19 & 0 & 0.01 & 0.05 & 0.08 & 0.11 & 0.13 & 0.22 & 0.22 & 0.3 & 0.25 & 0.22 & 0.12 \\
\hline 2 & 770 & 19 & 0 & 0.01 & 0.06 & 0.09 & 0.11 & 0.13 & 0.22 & 0.24 & 0.26 & 0.27 & 0.27 & 0.12 \\
\hline 3 & 670 & 18 & 0 & 0.04 & 0.09 & 0.11 & 0.15 & 0.21 & 0.25 & 0.28 & 0.31 & 0.32 & 0.31 & 0.16 \\
\hline 4 & 550 & 22 & 0 & 0.01 & 0.11 & 0.12 & 0.18 & 0.29 & 0.32 & 0.33 & 0.32 & 0.36 & 0.39 & 0.20 \\
\hline 5 & 520 & 22 & 0 & 0.1 & 0.11 & 0.14 & 0.19 & 0.34 & 0.35 & 0.36 & 0.41 & 0.41 & 0.43 & 0.2 \\
\hline 6 & 480 & 18 & 0 & 0.01 & 0.11 & 0.14 & 0.21 & 0.28 & 0.34 & 0.35 & 0.35 & 0.4 & 0.42 & 0.22 \\
\hline 7 & 380 & 25 & 0 & 0.11 & 0.16 & 0.17 & 0.31 & 0.33 & 0.33 & 0.32 & 0.34 & 0.45 & 0.42 & 0.24 \\
\hline 8 & 300 & 18 & 0 & 0.13 & 0.14 & 0.13 & 0.21 & 0.41 & 0.39 & 0.53 & 0.43 & 0.45 & 0.54 & 0.22 \\
\hline 9 & 260 & 25 & 0 & 0.16 & 0.17 & 0.2 & 0.2 & 0.5 & 0.45 & 0.46 & 0.5 & 0.54 & 0.56 & 0.26 \\
\hline 10 & 240 & 18 & 0 & 0.14 & 0.16 & 0.2 & 0.3 & 0.4 & 0.4 & 0.41 & 0.44 & 0.46 & 0.47 & 0.25 \\
\hline 11 & 210 & 22 & 0 & 0.16 & 0.17 & 0.2 & 0.25 & 0.4 & 0.45 & 0.46 & 0.5 & 0.51 & 0.66 & 0.27 \\
\hline * & - & - & 0 & 0.1 & 0.2 & 0.3 & 0.3 & - & 0.5 & - & - & - & 0.5 & - \\
\hline$* *$ & - & - & 0 & 0.05 & 0.1 & 0.2 & 0.3 & - & 0.5 & - & - & - & - & - \\
\hline
\end{tabular}

*Specified values in IS 3008 (1981) [11]; **Specified values in IS 3129 (1985) [12].

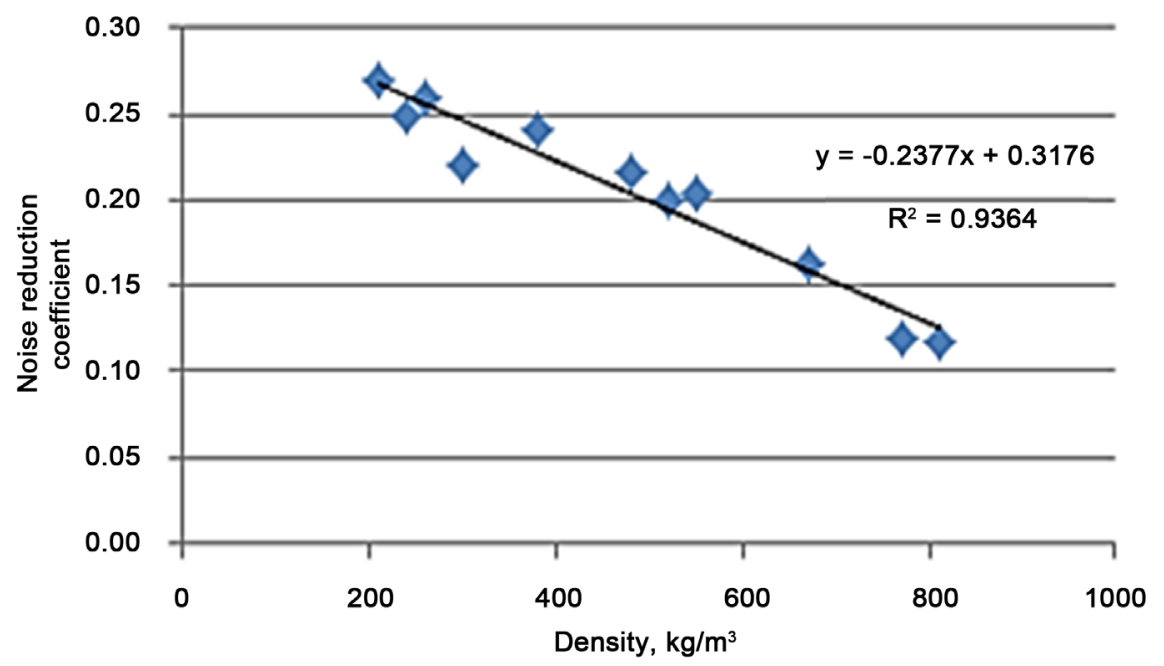

Figure 2. Effect of density on noise reduction coefficient of fibre board.

fibre board is as shown in Figure 2. From the results it can be said that sound is not able to penetrate through the pores or voids of panels with higher densities, resulting in more reflection of sound. The maximum values of sound absorption coefficient of samples are observed between 2500 to $4000 \mathrm{~Hz}$ frequencies.

The influence of thickness was also observed of samples having densities in the same range. Higher sound absorption was observed in thicker samples. Sound absorption of $25 \mathrm{~mm}$ thick sample with $260 \mathrm{~kg} / \mathrm{m}^{3}$ density was recorded higher than sample number 8 and 9 with thickness of $18 \mathrm{~mm}$ having densities of 300 and $240 \mathrm{~kg} / \mathrm{m}^{3}$ respectively as given in Table 1 , which shows that sound absorption values are observed in thicker sample is higher as compared to thinner 
samples. Also it is seen that absorption depends upon the construction of product, nature of material, porosity, type of surface and density. While studying sound absorption mechanism of porous materials the number, size and type of pores are the important factors to be considered. To allow sound dissipation by friction, the sound wave has to enter the porous material. This means, there should be enough pores on the surface of the material for the sound to pass through and get dampened [18].

It is observed from the results that the low density fibre boards have better sound absorption and sound absorption drops with increase in density. Maximum sound absorption coefficient of 0.66 is observed for lowest density (220 $\mathrm{kg} / \mathrm{m}^{3}$ ) particle board studied, at $4000 \mathrm{~Hz}$ frequency. At low frequencies (125 $\mathrm{Hz}$ ) lesser sound absorption coefficient in all samples were observed irrespective of density. Major increase in sound absorption coefficient is observed from 1000 $\mathrm{Hz}$ to $2000 \mathrm{~Hz}$ frequencies. One of the most important properties that effect the sound absorption property of a fibrous material is the specific flow resistance per unit thickness of the material. In general, it can be said that, always better sound absorption values are observed with higher airflow resistance. Also the surface area of fiber and size of fiber have great effect on the sound absorption properties.

Density of a material is considered to be one of the important factors which governs the sound absorption of any material. There is increase in sound absorption value in the middle and higher frequency as the density of the sample increased [19]. The number of fibers increases per unit area when the apparent density is large. Energy loss increases as the surface friction increases, thus the sound absorption coefficient increases. Less dense and more open structure absorbs sound of low frequencies $(500 \mathrm{~Hz})$. Denser structure performs better for frequencies above than $2000 \mathrm{~Hz}$. Various studies that dealt with sound absorption in porous materials have concluded that low frequency sound absorption has direct relationship with thickness. Ibrahim et al., [20] showed the increase of sound absorption only at low frequencies, as the material gets thicker. However, at higher frequencies thickness has insignificant effect on sound absorption.

\section{Conclusion}

Density is the crucial factor to determine the acoustic efficiency within the same type of composite; we can conclude that noise reduction coefficient increases with decrease in density and vice versa. From the results it can also be concluded that within the same type of composite with increase in voids/porosity the sound absorption/noise reduction coefficient increases. The acoustic property of low density fibre board is comparable with commercially available acoustic panel i.e. wood wool building slabs/board and low density particle boards.

\section{Acknowledgements}

The authors thank the Director, Indian Plywood Industries Research and Training Institute, Bangalore, India for his encouragement and support. 


\section{References}

[1] Takahashi, Y.T., Otsuru, T. and Tomiku, R. (2005) In Situ Measurements of Surface Impedance and Absorption Coefficients of Porous Materials Using Two Microphones and Ambient Noise. Applied Acoustics, 66, 845-865. https://doi.org/10.1016/j.apacoust.2004.11.004

[2] ISO 354 (2003) Acoustics-Measurement of Sound Absorption in a Reverberation Room, ISO, Geneva, Switzerland.

[3] Garai, M. and Guidorzi, P. (2015) Sound Reflection Measurements on Noise Barriers in Critical Conditions. Building and Environment, 94, 752-763. https://doi.org/10.1016/j.buildenv.2015.06.023

[4] Bell, L.H. (1994) Industrial Noise Control, Fundamentals and Applications. 2nd Edition, M. Dekker, New York.

[5] Aballea, F.E., Lissek, H. and Rene, P.J. (2008) Assessment of Different Low-Frequency Soundproofing Systems for Room Acoustics. Proceedings of $37^{\text {th }}$ International Congress and Exposition on Noise Control Engineering, Shanghai, 26-29 October 2008, 26-29.

[6] Seddeq, H.S. (2009) Factors Influencing Acoustic Performance of Sound Absorptive Materials. Australian Journal of Basic and Applied Sciences, 3, 4610-4617.

[7] Wang, C.N. and Torng, J.H. (2001) Experimental Study of the Absorption Characteristics of Some Porous Fibrous Materials. Applied Acoustics, 62, 447-459. https://doi.org/10.1016/S0003-682X(00)00043-8

[8] Sikora, J. and Turkiewicz, J. (2010) Sound Absorption Coefficients of Granular Materials. Mechanics and Control, 29, 149-157.

[9] Peng, L., Song, B., Wang, J. and Wang, D. (2015) Mechanic and Acoustic Properties of the Sound-Absorbing Material Made from Natural Fiber and Polyester. Advances in Materials Science and Engineering, 2015, Article ID: 274913. https://doi.org/10.1155/2015/274913

[10] Kucuk, M. and Korkmaz, Y. (2012) The Effect of Physical Parameters on Sound Absorption Properties of Natural Fiber Mixed Nonwoven Composites. Textile Research Journal, 82, 2043-2053. https://doi.org/10.1177/0040517512441987

[11] IS 3008 (1981) Specification for Wood Wool Building Slabs. Bureau of Indian Standards, New Delhi.

[12] IS 3129 (1985) Specification for Low Density Particle Board. Bureau of Indian Standards, New Delhi.

[13] Delany, M.E. and Bazley, E.N. (1970) Acoustical Properties of Fibrous Absorbent Materials. Applied Acoustics, 3, 105-116. https://doi.org/10.1016/0003-682X(70)90031-9

[14] Garai, M. and Pompoli, F. (2005) A Simple Empirical Model of Polyester Fibre Materials for Acoustical Applications. Applied Acoustics, 66, 1383-1398. https://doi.org/10.1016/j.apacoust.2005.04.008

[15] ASTM E-1050 (2008) Standard Test Method for Impedance and Absorption of Acoustical Materials Using a Tube, Two Microphones and a Digital Frequency Analysis System. American Society for Testing of Materials.

[16] IS 10420 (1982) Method of Determination of Sound Absorption Co-Efficient of Timber by Standing Wave Method. Bureau of Indian Standards, New Delhi.

[17] IS 2380 (1977) Methods of Test for Wood Particle Boards and Boards from Other Lignocellulosic Materials. Bureau of Indian Standards, New Delhi.

[18] Allard, J.F., Depollier, C. and Guignouard, P. (1989) Free Field Surface Impedance 
Measurements of Sound-Absorbing Materials with Surface Coatings. Applied Acoustics, 26, 199-207. https://doi.org/10.1016/0003-682X(89)90053-4

[19] Koizumi, T., Tsujiuchi, N. and Adachi, A. (2002) The Development of Sound Absorbing Materials Using Natural Bamboo Fibers, High Performance. WIT Press, Southampton.

[20] Ibrahim, M.A. and Melik, R.W. (1978) Physical Parameters Affecting Acoustic Absorption Characteristics of Fibrous Materials. Proceedings of the Mathematical and Physical Society of Egypt, 46, 125-130.

Submit or recommend next manuscript to SCIRP and we will provide best service for you:

Accepting pre-submission inquiries through Email, Facebook, LinkedIn, Twitter, etc. A wide selection of journals (inclusive of 9 subjects, more than 200 journals)

Providing 24-hour high-quality service

User-friendly online submission system

Fair and swift peer-review system

Efficient typesetting and proofreading procedure

Display of the result of downloads and visits, as well as the number of cited articles Maximum dissemination of your research work

Submit your manuscript at: http://papersubmission.scirp.org/

Or contact oja@scirp.org 